\title{
Similar Psychopathological Profiles in Female and Male Cushing's Disease Patients after Treatment but Differences in the Pathogenesis of Symptoms
}

\author{
Monika Milian Juergen Honegger Christine Gerlach Xenia Hemeling \\ Tsambika Psaras \\ Department of Neurosurgery, University Hospital Tübingen, Tübingen, Germany
}

\author{
Key Words \\ Cushing's disease - Gender differences · Psychopathology · \\ Depression · Hypocortisolism · Remission
}

\begin{abstract}
Background: Female Cushing's disease (CD) patients with active disease present more frequently with depression compared to their male co-sufferers. This study investigated whether the gender difference prevails after remission and whether gender-specific factors contributing to mental health exist. Methods: 72 biochemically cured CD patients (11 male, mean age $45.9 \pm 13.7$ years) who underwent transsphenoidal tumour removal filled out the Symptom Checklist-90-Revised inventory on average $42.1 \pm 32.9$ months after surgery. Multiple regression analyses included the following independent factors: (i) age, (ii) presence of comorbidities, (iii) presence of hypocortisolism, (iv) presence of hypopituitarism, (v) disease duration until diagnosis, (vi) time elapsed since surgery, and (vii) postoperative radiotherapy to predict postoperative psychopathology. Results: Regarding the Global Severity Index, $23.0 \%$ of the female and $27.3 \%$ of the male CD patients presented with abnormal scores. In all nine dimensions, psychopathological abnormalities were present in both female and male patients with the same frequency and intensity (each $p>0.05$ ). Prolonged time to diagnosis was a strong predictive factor for worse
\end{abstract}

psychopathological status only in male patients. Among female patients, only the presence of comorbidities and to some extent pituitary deficiencies were related to psychopathological status. Conclusions: During the remission phase of $C D$, female and male patients present with similar psychopathological profiles. In males, long-term biochemical effects of previous hypercortisolism seem to be salient for psychopathology. In contrast, in females, the presence of comorbidities/stressors they have to cope with is the predictive factor for psychopathology. The results underline gender differences in $C D$ and the need to separate them on various issues.

(c) 2014 S. Karger AG, Basel

\section{Introduction}

Cushing's syndrome (CS) is associated with a high rate of psychiatric manifestations $[1,2]$, mostly depression and anxiety. In florid CS and Cushing's disease (CD) approximately $54-81 \%$ of all patients presenting with a significant psychopathology [3-6] and a longer duration of CS bear an increased risk for the development of a psychiatric disorder [7]. The relationship between plasma ACTH levels and depression is discussed controversially $[1,3]$, probably owing to different classifications of depression. However, the urinary free cortisol levels were

\section{KARGER}

(c) 2014 S. Karger AG, Basel

0028-3835/14/1001-0009\$39.50/0

E-Mail karger@karger.com

www.karger.com/nen
Monika Milian

Department of Neurosurgery, University of Tübingen

Hoppe-Seyler-Strasse 3

DE-72076 Tübingen (Germany)

E-Mail monika.milian@med.uni-tuebingen.de 
significantly higher in patients with very severe depression [1] and in patients with depression compared to those without [3]. Prospective studies have shown that psychiatric symptoms improved significantly after successful treatment, but were still present after remission in a considerable portion (24-32\%) of the patients investigated $[4,5,8]$.

An important and noteworthy aspect of CD is that depressive symptoms are significantly more frequent in female CD patients with active disease when compared to their male counterparts $[3,9]$. This gender imbalance is also observed when the known female preponderance in depression and anxiety in the general population is taken into account [10-12]. This finding is insofar very interesting as $\mathrm{CD}$ appears at a younger age and with a more severe clinical presentation in males, compared with females, together with a more pronounced elevation of urinary free cortisol and ACTH levels [13].

To our knowledge there is no study available that investigates whether the above-described gender imbalance concerning psychopathological symptoms prevails after remission. In general, there are no studies looking at female and male patients separately, because most studies refer to the patient population as a whole.

The purpose of this study was twofold: First, to investigate a large cohort of cured CD patients in order to determine whether the relicts of CD have a different effect on the psychopathological profile in female and male patients. Second, we aimed to analyse in both genders whether disease duration until diagnosis, age, the presence of comorbidities, postoperative radiotherapy, hypopituitarism, time since surgery and hydrocortisone replacement therapy have an impact on postoperative mental health.

\section{Subjects and Methods}

\section{Patients}

We report on 72 biochemically cured CD patients (61 females, 11 males) with a mean age of $45.9 \pm 13.7$ years (range $22-76$ ) and a mean educational level of $13.2 \pm 2.8$ years (range $7-18$ ). The operations were performed by one neurosurgeon (J.H.) at the University Hospital in Freiburg (1998-2004) and at the University Hospital in Tübingen (2004-2013). Data collection was carried out successively between 2008 and 2013. The patients operated for CD were contacted either per mail or during their follow-up visit and they were asked to complete a questionnaire dealing with psychopathological symptoms. The mean follow-up time since their operative treatment was $42.1 \pm 32.9$ months (range 3-132). All patients underwent transsphenoidal surgery and the estimated mean time until diagnosis (i.e. time from onset of symptoms to diagnosis) was $5.3 \pm 4.1$ years (range 0.5-16). The presence of comorbidities and clinical signs of the disease was documented by analysing the records of the patients. As comorbidities following phenomena were considered: overweight, diabetes, hypertension, osteoporosis, cognitive deficits, fatigue, loss of libido, hair loss, hirsutism, muscle weakness, depression and menstrual disorder.

Complete endocrinological data were available in all patients and all patients fulfilled remission criteria at the time of the postoperative survey. Patients were considered as cured with a 24-hour urinary cortisol excretion $<80 \mu \mathrm{g} / 24 \mathrm{~h}(<220 \mathrm{nmol} / 24 \mathrm{~h})$, a persistent postoperative morning serum cortisol level $<2 \mu \mathrm{g} / \mathrm{dl}(\sim 50$ $\mathrm{nmol} / \mathrm{l}$ ) and/or a suppression in the 2-mg dexamethasone suppression test $<2 \mu \mathrm{g} / \mathrm{dl}(\sim 50 \mathrm{nmol} / \mathrm{l})$ [14]. Hypocortisolism after transsphenoidal tumour removal was encountered in 34 patients (47.2\%). Postoperative radiotherapy was performed in 6 patients $(8.3 \%)$. Substitution therapy of at least one pituitary axis (i.e. gonadotrophin deficiency, GH deficiency, TSH deficiency) was encountered in 26 patients $(36.1 \%)$. Table 1 presents the detailed demographic and clinical data of all patients.

The research protocol was approved by the Ethics Committee of the University of Tübingen (Tübingen, Germany) and was performed under the tenets of the Declaration of Helsinki and its subsequent amendments. Written informed consent was given by all patients prior to participating in the study.

\section{Instruments}

Symptom Checklist-90-Revised Questionnaire

The Symptom Checklist-90-Revised (SCL-90-R) is a 90 -item self-report symptom inventory [15] to measure psychological symptoms and psychological distress. It is designed to be appropriate for use with individuals from the community as well as individuals with either medical or psychiatric conditions. The SCL90-R assesses psychological distress in terms of nine primary symptom dimensions and three summary scores termed global scores. Items are rated on a 5-point scale ranging from $0=$ not at all to $4=$ extremely. The principal symptom dimensions are labelled somatization (SOM), obsessive-compulsive (OBS), interpersonal sensitivity (INT), depression (DEP), anxiety (ANX), hostility (HOS), phobic anxiety (PHOB), paranoid ideation (PAR), and psychoticism (PSY). The global measures are referred to as the Global Severity Index (GSI, indicates the basic psychological distress), the Positive Symptom Distress Index (PSDI, indicates the intensity of psychological distress), and the Positive Symptom Total (PST, indicates the frequency of psychological distress).

The validity of the raw scores is limited [15]. Only the transformation to $\mathrm{T}$ scores, which take into account sociodemographic factors, allows the classification of the individual case in relation to deviations from the average. Age- and sex-related German reference values were derived from the German manual [16]. Higher $\mathrm{T}$ scores indicate higher distress or disturbance in the dimension described and a $\mathrm{T}$ score $>60$ (corresponding to a standard deviation) is considered pathological.

\section{Statistical Analysis}

Data were analysed using SPPS (Statistical Package for Social Sciences) version 20.0 for Windows. The normality of the data was verified with the Kolmogorov-Smirnov test. Descriptive statistics were used to analyse sociodemographic and clinical characteristics (age, level of education, time to diagnosis, time since surgery) using mean and standard deviations for parametric data. The number of patients was used for categorical variables (e.g. gender, number of patients with hypocortisolism). Parametric data between the gen- 
Table 1. Demographic and clinical data of all patients

\begin{tabular}{lcccc}
\hline & $\begin{array}{l}\text { Total } \\
(\mathrm{n}=72)\end{array}$ & $\begin{array}{l}\text { Female } \\
(\mathrm{n}=61)\end{array}$ & $\begin{array}{l}\text { Male } \\
(\mathrm{n}=11)\end{array}$ & $\mathrm{p}$ \\
\hline Age, years & $45.9 \pm 13.7$ & $45.0 \pm 14.2$ & $50.8 \pm 8.9$ & 0.200 \\
Education, years & $13.2 \pm 2.8$ & $13.1 \pm 2.8$ & $13.5 \pm 3.0$ & 0.637 \\
Time to diagnosis, years & $5.3 \pm 4.1$ & $4.9 \pm 4.0$ & $7.4 \pm 4.2$ & 0.064 \\
Time since surgery, months & $42.1 \pm 32.9$ & $42.6 \pm 34.9$ & $39.2 \pm 19.4$ & 0.756 \\
Hypocortisolism, yes/no & $34 / 38$ & $28 / 33$ & $6 / 5$ & 0.597 \\
Hypopituitarism, yes/no & $26 / 46$ & $23 / 38$ & $3 / 8$ & 0.735 \\
Radiotherapy, yes/no & $6 / 66$ & $5 / 56$ & $1 / 10$ & 1.000 \\
Comorbidities, yes/no & $55 / 17$ & $49 / 12$ & $6 / 5$ & 0.116
\end{tabular}

Hypocortisolism = Presence of hypocortisolism; Hypopituitarism = at least one deficiency of either the gonadotroph, GH, or TSH axis. The p value indicates significant differences between female and male patients.

Table 2. Comparison of $\mathrm{T}$ scores between female and male patients in the respective domains of the SCL-90-R

\begin{tabular}{|c|c|c|c|c|}
\hline & $\begin{array}{l}\text { Total } \\
(\mathrm{n}=72)\end{array}$ & $\begin{array}{l}\text { Female } \\
(n=61)\end{array}$ & $\begin{array}{l}\text { Male } \\
(n=11)\end{array}$ & $\mathrm{p}$ \\
\hline Somatization & $55.8 \pm 9.7$ & $55.6 \pm 10.1$ & $56.6 \pm 7.7$ & 0.748 \\
\hline Obsessive-compulsive & $55.9 \pm 9.2$ & $56.2 \pm 9.1$ & $53.9 \pm 9.7$ & 0.448 \\
\hline Interpersonal sensitivity & $54.0 \pm 8.8$ & $54.0 \pm 8.8$ & $54.0 \pm 9.6$ & 1.000 \\
\hline Depression & $56.3 \pm 8.8$ & $56.2 \pm 8.6$ & $56.9 \pm 10.1$ & 0.820 \\
\hline Anxiety & $53.3 \pm 8.6$ & $52.7 \pm 8.6$ & $56.9 \pm 7.7$ & 0.134 \\
\hline Hostility & $52.7 \pm 9.7$ & $52.4 \pm 9.4$ & $53.8 \pm 11.5$ & 0.668 \\
\hline Phobic anxiety & $51.6 \pm 9.3$ & $51.6 \pm 9.4$ & $51.5 \pm 9.1$ & 0.965 \\
\hline Paranoid ideation & $50.5 \pm 9.5$ & $50.7 \pm 9.5$ & $49.5 \pm 9.7$ & 0.715 \\
\hline Psychoticism & $53.9 \pm 9.0$ & $53.6 \pm 9.3$ & $55.4 \pm 7.6$ & 0.551 \\
\hline GSI & $55.3 \pm 8.8$ & $55.2 \pm 8.7$ & $56.4 \pm 9.2$ & 0.679 \\
\hline PSDI & $54.1 \pm 9.5$ & $54.7 \pm 9.7$ & $50.6 \pm 8.3$ & 0.194 \\
\hline PST & $54.3 \pm 9.2$ & $54.0 \pm 9.4$ & $56.5 \pm 8.4$ & 0.394 \\
\hline
\end{tabular}

The $\mathrm{p}$ value indicates significant differences between female and male patients.

ders were compared using the independent samples t test. Differences in categorical data were evaluated with $\chi^{2}$ statistics or Fisher's exact test, as appropriate. We performed stepwise multiple linear regression analyses to identify variables that affect postoperative psychopathological status. The significance level was set at $\mathrm{p}<0.05$.

\section{Results}

\section{Clinical Data}

Female and male CD patients did not differ significantly with regard to age, education, time since surgery, the presence of hypocortisolism, the presence of hypopituitarism, the presence of comorbidities and postopera- tive radiotherapy. There was only a slight but not significant trend towards a longer time to diagnosis in male compared to female patients (table 1).

\section{Frequency and Intensity of Psychopathological}

Symptoms in All Patients

Symptoms of somatization were observed in $36.1 \%$, obsessive-compulsive behaviour in $29.2 \%$, interpersonal sensitivity in $18.1 \%$, depression in $26.4 \%$, anxiety in $22.2 \%$, hostility in $18.1 \%$, phobic anxiety in $18.1 \%$, paranoid ideation in $16.7 \%$, and psychoticism in $22.2 \%$ of all patients. The GSI was abnormal in $23.6 \%$, the PSDI in $25.0 \%$, and the PST in $18.1 \%$ of the patients. The mean T scores of the whole patient group are presented in table 2 . 


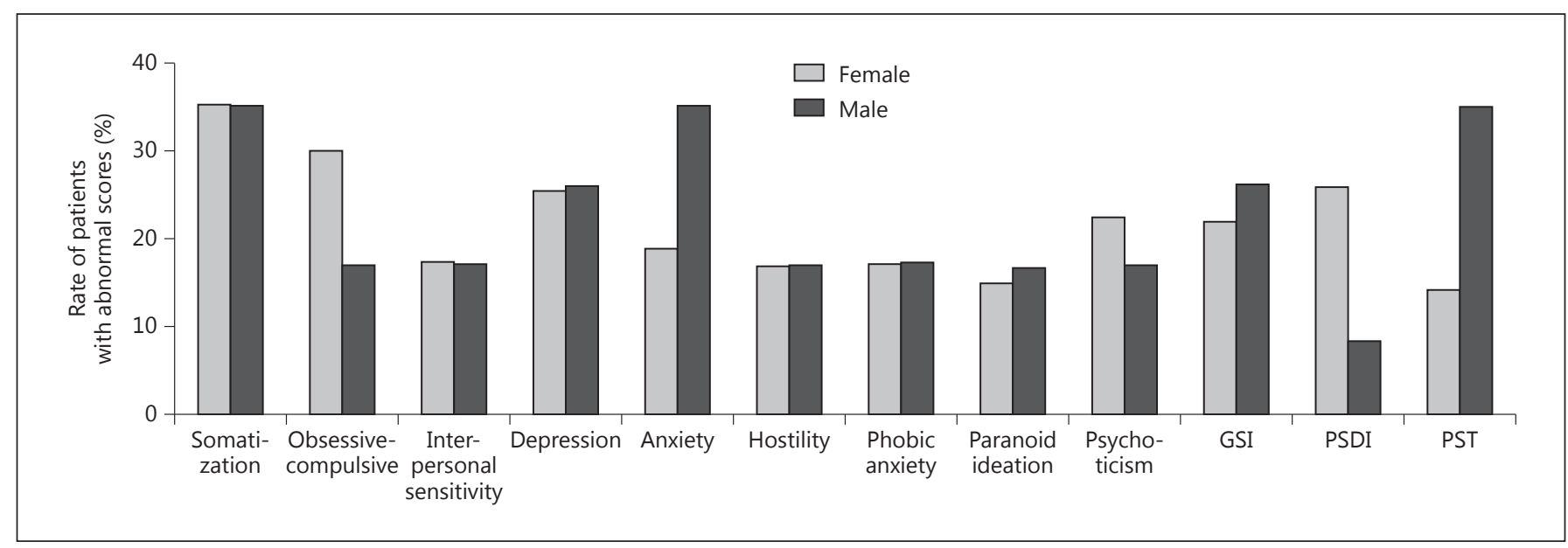

Fig. 1. Rate of patients presenting pathological scores in the SCL-90-R in the respective domains compared to age- and sex-matched controls. No significant differences between female and male patients could be found (each $\mathrm{p}>0.05)$.

\section{Frequency and Intensity of Psychopathological} Symptoms in Female and Male Patients

Figure 1 demonstrates the frequency and table 2 the intensity of psychopathological symptoms in female and male patients in each dimension.

No significant difference could be observed in the frequency of psychopathology between female and male patients: somatization ( 36.1 vs. $36.4 \%, p=1.000)$, obsessivecompulsive behaviour ( 31.1 vs. $18.2 \%, \mathrm{p}=0.491$ ), interpersonal sensitivity ( 18.0 vs. $18.2 \%, \mathrm{p}=1.000)$, depression ( 26.2 vs. $27.3 \%, \mathrm{p}=1.000$ ), anxiety ( 19.7 vs. $36.4 \%, \mathrm{p}=$ 0.247 ), hostility ( 18.0 vs. $18.2 \%, \mathrm{p}=1.000$ ), phobic anxiety (18.0 vs. $18.2 \%, \mathrm{p}=1.000)$, paranoid ideation (16.4 vs. $18.2 \%, \mathrm{p}=1.000)$, psychoticism $(23.0$ vs. $18.2 \%) \mathrm{p}=$ $1.000)$, GSI (23.0 vs. $27.3 \%, \mathrm{p}=0.714)$, PSDI (27.9 vs. $9.1 \%, \mathrm{p}=0.271)$, and PST ( 14.8 vs. $36.4 \%, \mathrm{p}=0.103)$. Interestingly, there was even a tendency towards a higher frequency of anxiety and psychological distress (PST) in male patients compared to female patients.

\section{Stepwise Multiple Linear Regression Analyses to}

Predict Postoperative Psychological Symptoms

Stepwise linear regression analyses were conducted to identify variables that affect postoperative psychopathology. The following independent variables: age, presence of comorbidities, presence of hypocortisolism, presence of hypopituitarism, time to diagnosis, time since surgery and postoperative radiotherapy were included in the model. The rationale of the chosen factors for the regression analyses were that previous studies already discussed effects of hypopituitarism (here also including replacement of glucocorticoids) [17] and comorbidities [18] on either psychiatric status or quality of life in CD. Pituitary radiation was shown to have little [19] or no effect [17, 20, 21] on quality of life outcomes. To date, time elapsed since surgery $[17,20]$ and age $[20,21]$ were not significantly correlated with quality of life.

\section{Female CD Patients}

Table 3 shows the predictive factors for postoperative psychological symptoms in female patients. The 'presence of comorbidities' was the sole predictor for several subscales (each $\mathrm{p}<0.05$ ) and the total scores of the SCL-90-R, i.e. the GSI $\left(\mathrm{R}^{2}=0.111, \mathrm{p}<0.01\right)$ and the PST $\left(\mathrm{R}^{2}=0.092, \mathrm{p}<0.05\right)$, meaning that psychopathological symptoms were increased in female patients with existing comorbidities. Psychoticism was best predicted by the variables 'hypocortisolism', and additionally 'hypopituitarism' $\left(\mathrm{R}^{2}=0.140, \mathrm{p}<0.05\right)$. No other variable explained additional variance.

\section{Male CD Patients}

Table 4 shows the predictive factors for postoperative psychological symptoms in male patients. The variable 'time to diagnosis' was related to postoperative somatization $\left(R^{2}=0.516, p<0.05\right)$, interpersonal sensitivity $\left(R^{2}=\right.$ $0.516, \mathrm{p}<0.05)$, depression $\left(\mathrm{R}^{2}=0.581, \mathrm{p}<0.05\right)$, anxiety $\left(\mathrm{R}^{2}=0.372, \mathrm{p}<0.05\right)$, paranoid ideation $\left(\mathrm{R}^{2}=0.853, \mathrm{p}<\right.$ $0.001)$, psychoticism $\left(\mathrm{R}^{2}=0.620, \mathrm{p}<0.01\right)$, the GSI $\left(\mathrm{R}^{2}=\right.$ $0.619, \mathrm{p}<0.01)$, the PSDI $\left(\mathrm{R}^{2}=0.494, \mathrm{p}<0.05\right)$, and the PST $\left(\mathrm{R}^{2}=0.514, \mathrm{p}<0.05\right)$, meaning that the longer the 
Table 3. Predictive factors for postoperative psychopathology (T scores) based on stepwise multiple linear regression analyses in female patients $(n=61)$

\begin{tabular}{|c|c|c|c|c|c|c|c|}
\hline & Age & Comorbidities & Hypocortisolism & Hypopituitarism & TTD & TSS & Radio \\
\hline Somatization & 0.566 & 0.019 & 0.820 & 0.871 & 0.977 & 0.119 & 0.758 \\
\hline Obsessive-compulsive & 0.077 & 0.003 & 0.176 & 0.290 & 0.696 & 0.681 & 0.930 \\
\hline Interpersonal sensitivity & - & - & - & - & - & - & - \\
\hline Depression & 0.236 & 0.040 & 0.239 & 0.526 & 0.827 & 0.969 & 0.993 \\
\hline Anxiety & 0.584 & 0.044 & 0.312 & 0.755 & 0.511 & 0.539 & 0.825 \\
\hline Hostility & - & - & - & - & - & - & - \\
\hline Phobic anxiety & - & - & - & - & - & - & - \\
\hline Paranoid ideation & - & - & - & - & - & - & - \\
\hline Psychoticism & 0.495 & 0.919 & 0.030 & 0.044 & 0.905 & 0.151 & 0.634 \\
\hline GSI & 0.476 & 0.009 & 0.306 & 0.565 & 0.880 & 0.434 & 0.824 \\
\hline PSDI & - & - & - & - & - & - & - \\
\hline PST & 0.321 & 0.017 & 0.197 & 0.418 & 0.841 & 0.675 & 0.806 \\
\hline
\end{tabular}

Hypocortisolism = Presence of hypocortisolism; Hypopituitarism = at least one deficiency of either the gonadotroph, GH, or TSH axis; TTD = time to diagnosis, TSS = time since surgery; Radio = radiotherapy; $-=$ no model computation. Significant $\mathrm{p}$ values are in bold.

Table 4. Predictive factors for postoperative psychopathology (T scores) based on stepwise multiple linear regression analyses in male patients $(\mathrm{n}=11)$

\begin{tabular}{|c|c|c|c|c|c|c|c|}
\hline & Age & Comorbidities & Hypocortisolism & Hypopituitarism & TTD & TSS & Radio \\
\hline Somatization & 0.391 & 0.094 & 0.122 & 0.050 & 0.013 & 0.428 & 0.318 \\
\hline Obsessive-compulsive & 0.111 & 0.016 & 0.689 & 0.140 & 0.219 & 0.291 & 0.052 \\
\hline Depression & 0.260 & 0.799 & 0.332 & 0.108 & 0.006 & 0.593 & 0.167 \\
\hline Anxiety & 0.983 & 0.863 & 0.521 & 0.055 & 0.046 & 0.210 & 0.188 \\
\hline Hostility & 0.858 & 0.093 & 0.462 & 0.286 & 0.235 & 0.833 & 0.008 \\
\hline Psychoticism & 0.602 & 0.383 & 0.793 & 0.242 & 0.004 & 0.532 & 0.639 \\
\hline GSI & 0.950 & 0.300 & 0.132 & 0.081 & 0.004 & 0.215 & 0.321 \\
\hline PSDI & 0.052 & 0.549 & 0.427 & 0.098 & 0.016 & 0.542 & 0.620 \\
\hline PST & 0.705 & 0.308 & 0.343 & 0.107 & 0.013 & 0.353 & 0.172 \\
\hline
\end{tabular}

Hypocortisolism = Presence of hypocortisolism; Hypopituitarism = at least one deficiency of either the gonadotroph, GH, or TSH axis; TTD = time to diagnosis, TSS = time since surgery; Radio = radiotherapy. Significant $\mathrm{p}$ values are in bold.

duration of hypercortisolism, the more pronounced were the psychopathological symptoms (fig. 2).

The presence of hypopituitarism explained, besides the variable time to diagnosis, an additional $19.3 \%$ of the variance for somatization, meaning that both variables together explained 70.9\%. Obsessive-compulsive behaviour was best predicted by the independent variable 'presence of comorbidities' $\left(R^{2}=0.494, p<0.05\right)$, and hostil- ity was best predicted by the independent variable 'radiotherapy' $\left(\mathrm{R}^{2}=0.566, \mathrm{p}<0.01\right)$. Phobic anxiety was best predicted by the independent variable 'presence of hypocortisolism' ( $\left.\mathrm{R}^{2}=0.402, \mathrm{p}<0.05\right)$. Overall, the time to diagnosis explained in the majority of scales more than $50 \%$ of the variance for psychopathological symptoms, and it was even $85.3 \%$ in the scale 'paranoid ideation'. 


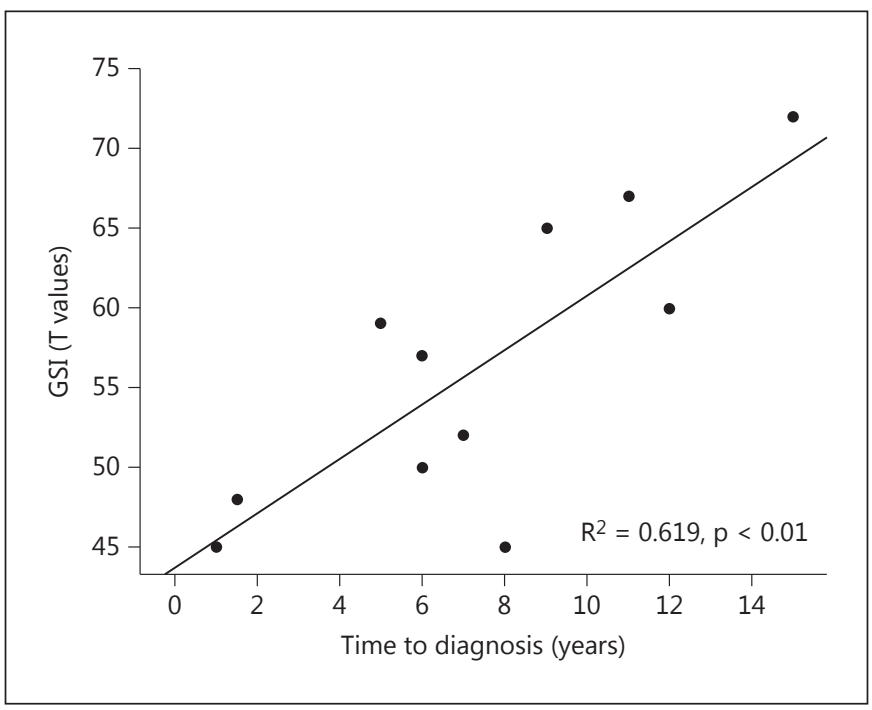

Fig. 2. Correlation between the time to diagnosis interval and the postoperative GSI of the SCL-90-R in male CD patients.

\section{Discussion}

Female patients are more frequently depressed than male patients in the overt phase of $\mathrm{CD}[3,9]$, although $\mathrm{CD}$ appears with a more severe clinical manifestation in males compared to females [13]. Thus, we suspect that in female patients an additional internal variable interacts between the clinical disease manifestation and the psychological condition. There is evidence that sex differences in the use of coping styles in response to stress are salient and contributing factors in the pathogenesis of anxiety and depression in women [22]. Two categories of coping behaviour have been referred to in the literature: problem-focused and emotion-focused coping [23], the latter associated with self-blame, venting and rumination. Indeed, women tend to use emotion-focussed coping strategies to manage stressors and these strategies are more often associated with depression and anxiety [24]. This might be a reason for the higher prevalence rates of depression and anxiety in women in the general population [11].

To date, no gender-related data is available concerning the psychopathological symptoms after $\mathrm{CD}$ has been cured. Therefore, we collected data from a large patient cohort that had been successfully treated for CD. The average postoperative time interval was 3.5 years. The SCL$90-\mathrm{R}$ was filled out by 61 female and 11 male patients. Concerning the gender distribution of our patients, we found a clear predominance of the female gender with a ratio of approximately 5:1 as described before [25]. The two gender groups did not differ significantly with respect to any clinical or demographic data. There was only a trend towards a longer time until diagnosis in male compared to female patients. Similarly, a previous study did not find significant differences between females and males in the time interval elapsed between the appearance of first symptoms of hypercortisolism and its diagnosis [13].

Our analyses showed that the frequency of psychopathological symptoms does not differ between cured female and male CD patients in any of the nine scales. Regarding the GSI, $23.0 \%$ of the female and $27.3 \%$ of the male CD patients presented with abnormal scores when compared to age- and sex-matched controls. Similar rates of psychiatric pathology after recovery of hypercortisolism were previously reported $[4,5]$.

A further interesting finding of this study is that in male patients the time from onset of symptoms until diagnosis, i.e. the time period during which the individual is exposed to glucocorticoid excess, is very crucial for the postoperative psychological state. In our cohort, the time to diagnosis explained $85 \%$ of the variance for paranoid ideation and more than $60 \%$ for the GSI. Several authors discuss that increased affective symptoms in humans even after the normalization of their cortisol status suggest irreversible effects of glucocorticoid excess on the central nervous system [26, 27]. Thus, the results of this study highlight once more the paramount importance of an early disease detection in order to be able to limit irreversible damages that are evoked by a prolonged chronic glucocorticoid excess.

However, in female patients there was no direct effect of time to diagnosis on psychopathological status at all. Only the presence of comorbidities, and in one domain pituitary deficiencies, was associated with psychopathological status, strongly suggesting that the stressors female CD patients have to cope with play the main role in the pathogenesis of psychiatric disorders. In our previous study we identified variables that predict several domains of postoperative quality of life, one of them being depression [18]. We observed in a cohort of $17 \mathrm{pa}-$ tients (of whom $82.4 \%$ were female) that postoperative depression scores were best predicted by the number of postoperative comorbidities. Perhaps the dealing with comorbidities is salient for the development of depression, since the more comorbidities exist, the more coping with stress is demanded by the patients. Tiemensma et al. [28] investigated coping strategies in patients after
14

Neuroendocrinology 2014;100:9-16 DOI: $10.1159 / 000364878$
Milian/Honegger/Gerlach/Hemeling/ Psaras 
treatment for pituitary adenomas $(\mathrm{CD}$, acromegaly and non-functioning pituitary adenomas) and found that patients with pituitary adenomas reported less effective coping strategies compared with healthy controls. Yet, an important difference between the different pituitary diseases was that patients treated for CD, of whom $85.7 \%$ were female, sought more social support and thus in this domain more effective coping strategies compared to patients that had been treated for non-functioning pituitary adenomas. The authors assumed that $\mathrm{CD}$ patients suffer from more severe long-term effects compared to patients with non-functioning pituitary adenomas and that these impairments could be invalidating in everyday life, which in turn could lead to a higher need for social support. Nonetheless, the investigated CD patients display different and less effective coping strategies compared with healthy controls.

A further important reason for the differences in observed associations between female and male patients might be that females present with different personality traits compared to men. For instance, women are known to score higher on harm avoidance scales (i.e. anxious vs. risk-taking) [29], and that in turn high levels of harm avoidance and low level of self-directedness are marker of emotional vulnerability to depression [30]. In CD, Tiemensma et al. [27] found in a cohort of 51 long-term cured CD patients ( $84 \%$ female) an increased prevalence of maladaptive personality traits which might be related to the psychopathology in CD. Similarly, Dimopoulou et al. [31] reported on a sample of $50 \mathrm{CD}$ patients $(82 \% \mathrm{fe}-$ male), the majority being biochemically cured, that they indicated less novelty-seeking behaviour and presented with more anticipatory worries and pessimism as well as a higher fear of uncertainty compared to mentally healthy controls.

Besides problematic coping strategies and different personality traits in female patients, gonadal hormones could potentially have an additional influence on the observed disparities. Women are more likely to experience mood disturbances during times of hormonal flux, while testosterone may have protective benefits against anxiety and depression [32]. As a consequence, an additional triggering factor for the psychological status in female patients could be the complex interactions of hormonal diversities.

The other investigated variables had no influence (i.e. age, time since surgery) or little influence (i.e. hypocortisolism, hypopituitarism and postoperative radiotherapy) on psychopathology in this study. The presence of hypocortisolism was associated with phobic anxiety in male and psychoticism in female patients. Hypopituitarism, i.e. at least one deficiency of either the gonadotroph, $\mathrm{GH}$ or TSH axis, was correlated with somatization in male and psychoticism in female patients. Postoperative radiotherapy had no systematic effect on psychopathology in this study. Pituitary radiation $[17,20,21]$, time elapsed since surgery $[17,20]$ and age $[20,21]$ were shown to have no effect on quality of life outcomes in previous studies as well.

\section{Limitations of the Study}

A limitation of the study is the use of one single instrument, i.e. the SCL-90-R, to assess psychopathology. This may limit the coverage of the total psychopathology profile related to $\mathrm{CD}$, for instance apathy. Still, the most frequent symptoms such as depression and anxiety were assessed with the inventory. A statistical limitation of the study is the small male patient group when calculating regression analyses. This is due to the rarity of the disease with a clear predominance of the female gender, which makes it difficult to form large groups of male CD patients in a single-centre setting. Furthermore, there was a trend towards a longer duration until diagnosis in male compared to female patients and it might be possible that the duration until diagnosis therefore had a stronger effect on psychopathology compared to female patients. Finally, because of the cross-sectional design of the study, one should be careful in the deduction of cause-effect relationships.

\section{Conclusions}

Other than in active $\mathrm{CD}$, cured female and male patients present with a similar psychopathological profile. However, the triggering factors for the psychological status differ significantly between the two genders. In cured male patients, psychopathological abnormalities seem to represent late biochemical effects of prolonged previous hypercortisolism, while in cured female patients the comorbidities/stressors that have to be overcome influence the intensity of psychopathological symptoms.

This study indicates that there is a difference in the pathogenesis of psychopathological symptoms between female and male CD patients. Further studies are needed in order to investigate whether these findings also apply to health-related quality of life. 


\section{References}

1 Starkman MN, Schteingart DE: Neuropsychiatric manifestations of patients with Cushing's syndrome. Relationship to cortisol and adrenocorticotropic hormone levels. Arch Intern Med 1981;141:215-219.

-2 Trethowan WH, Cobb S: Neuropsychiatric aspects of Cushing's syndrome. AMA Arch Neurol Psychiatry 1952;67:283-309.

-3 Sonino N, Fava GA, Raffi AR, Boscaro M, Fallo F: Clinical correlates of major depression in Cushing's disease. Psychopathology 1998;31: 302-306.

$\checkmark 4$ Dorn LD, Burgess ES, Friedman TC, Dubbert B, Gold PW, Chrousos GP: The longitudinal course of psychopathology in Cushing's syndrome after correction of hypercortisolism. J Clin Endocrinol Metab 1997;82:912-919.

$\checkmark 5$ Kelly WF, Kelly MJ, Faragher B: A prospective study of psychiatric and psychological aspects of Cushing's syndrome. Clin Endocrinol 1996;45:715-720.

6 Loosen PT, Chambliss B, DeBold CR, Shelton $\mathrm{R}$, Orth DN: Psychiatric phenomenology in Cushing's disease. Pharmacopsychiatry 1992; 25:192-198.

-7 Dorn LD, Burgess ES, Dubbert B, Simpson SE, Friedman T, Kling M, Gold PW, Chrousos GP: Psychopathology in patients with endogenous Cushing's syndrome: 'atypical' or melancholic features. Clin Endocrinol 1995;43: 433-442.

-8 Espinosa-de-Los-Monteros AL, Sosa E, Martinez N, Mercado M: Persistence of Cushing's disease symptoms and comorbidities after surgical cure: a long-term, integral evaluation. Endocr Pract 2013;19:252-258.

$>9$ Milian M, Teufel P, Honegger J, Gallwitz B, Schnauder G, Psaras T: The development of the Tuebingen Cushing's disease quality of life inventory (Tuebingen CD-25). Part II: Normative data from 1,784 healthy people. Clin Endocrinol 2012;76:861-867.

$>10$ Ferrari AJ, Somerville AJ, Baxter AJ, Norman R, Patten SB, Vos T, Whiteford HA: Global variation in the prevalence and incidence of major depressive disorder: a systematic review of the epidemiological literature. Psychol Med 2013;43:471-481.

$>11$ Kuehner C: Gender differences in unipolar depression: an update of epidemiological findings and possible explanations. Acta Psychiatr Scand 2003;108:163-174.
12 Baxter AJ, Scott KM, Vos T, Whiteford HA: Global prevalence of anxiety disorders: a systematic review and meta-regression. Psychol Med 2013;43:897-910.

13 Pecori Giraldi F, Moro M, Cavagnini F, Study Group on the Hypothalamo-Pituitary-Adrenal Axis of the Italian Society of E: Genderrelated differences in the presentation and course of Cushing's disease. J Clin Endocrinol Metab 2003;88:1554-1558.

14 Biller BM, Grossman AB, Stewart PM, Melmed S, Bertagna X, Bertherat J, Buchfelder M, Colao A, Hermus AR, Hofland LJ, Klibanski A, Lacroix A, Lindsay JR, NewellPrice J, Nieman LK, Petersenn S, Sonino N, Stalla GK, Swearingen B, Vance ML, Wass JA, Boscaro M: Treatment of adrenocorticotropin-dependent Cushing's syndrome: a consensus statement. J Clin Endocrinol Metab 2008;93:2454-2462.

15 Derogatis L: SCL-90-R, Administration, Scoring \& Procedures Manual-I for the R(evised) Version. Baltimore, John Hopkins University School of Medicine, 1977.

16 Franke GH: SCL-90-R - die SymptomCheckliste von L.R. Derogatis (2. vollständig überarbeitete und neu normierte Auflage). Göttingen, Beltz Test, 2002.

17 Van Aken MO, Pereira AM, Biermasz NR, van Thiel SW, Hoftijzer HC, Smit JW, Roelfsema F, Lamberts SW, Romijn JA: Quality of life in patients after long-term biochemical cure of Cushing's disease. J Clin Endocrinol Metab 2005;90:3279-3286.

18 Milian M, Honegger J, Teufel P, Wolf A, Psaras T: Tuebingen CD-25 is a sensitive tool to investigate health-related quality of life in Cushing's disease patients in the course of the disease. Neuroendocrinology 2013;98:188199.

19 Lindsay JR, Nansel T, Baid S, Gumowski J, Nieman LK: Long-term impaired quality of life in Cushing's syndrome despite initial improvement after surgical remission. J Clin Endocrinol Metab 2006;91:447-453.

20 Webb SM, Badia X, Barahona MJ, Colao A, Strasburger CJ, Tabarin A, van Aken MO, Pivonello R, Stalla G, Lamberts SW, Glusman JE: Evaluation of health-related quality of life in patients with Cushing's syndrome with a new questionnaire. Eur J Endocrinol 2008; 158:623-630.
21 Santos A, Resmini E, Martinez-Momblan MA, Crespo I, Valassi E, Roset M, Badia X, Webb SM: Psychometric performance of the Cushing QoL questionnaire in conditions of real clinical practice. Eur J Endocrinol 2012; 167:337-342.

22 Nolen-Hoeksema S, Larson J, Grayson C: Explaining the gender difference in depressive symptoms. J Pers Soc Psychol 1999;77:10611072.

23 Billings AG, Moos RH: Coping, stress, and social resources among adults with unipolar depression. J Pers Soc Psychol 1984;46:877-891.

24 Mazure CM, Maciejewski PK: The interplay of stress, gender and cognitive style in depressive onset. Arch Womens Ment Health 2003; 6:5-8.

25 Orth DN: Cushing's syndrome. N Engl J Med 1995;332:791-803.

-26 Heald AH, Ghosh S, Bray S, Gibson C, Anderson SG, Buckler H, Fowler HL: Long-term negative impact on quality of life in patients with successfully treated Cushing's disease. Clin Endocrinol 2004;61:458-465.

27 Tiemensma J, Biermasz NR, Middelkoop HA, van der Mast RC, Romijn JA, Pereira AM: Increased prevalence of psychopathology and maladaptive personality traits after long-term cure of Cushing's disease. J Clin Endocrinol Metab 2010;95:E129-E141.

28 Tiemensma J, Kaptein AA, Pereira AM, Smit JW, Romijn JA, Biermasz NR: Coping strategies in patients after treatment for functioning or nonfunctioning pituitary adenomas. J Clin Endocrinol Metab 2011;96:964-971.

29 Miettunen J, Veijola J, Lauronen E, Kantojarvi L, Joukamaa M: Sex differences in Cloninger's temperament dimensions - a metaanalysis. Compr Psychiatry 2007;48:161-169.

-30 Cloninger CR, Svrakic DM, Przybeck TR: Can personality assessment predict future depression? A twelve-month follow-up of 631 subjects. J Affect Disord 2006;92:35-44.

>31 Dimopoulou C, Ising M, Pfister H, Schopohl J, Stalla GK, Sievers C: Increased prevalence of anxiety-associated personality traits in patients with Cushing's disease: a cross-sectional study. Neuroendocrinology 2013;97:139145.

32 McHenry J, Carrier N, Hull E, Kabbaj M: Sex differences in anxiety and depression: role of testosterone. Front Neuroendocrinol 2014; $35: 42-57$ 